\title{
Metallomics
}

Cite this: Metallomics, 2013, 5, 110

Received 1st August 2012, Accepted 4th December 2012 DOI: $10.1039 / c 2 m t 20156 a$ www.rsc.org/metallomics

\section{Lysosomal metal, redox and proton cycles influencing the CysHis cathepsin reaction}

\author{
Thomas D. Lockwood*
}

\begin{abstract}
In the 1930's pioneers discovered that maximal autolysis in tissue homogenates requires metal chelator, sulfhydryl reducing agent and acid $\mathrm{pH}$. However, metals, reducing equivalents and protons (MR\&P) have been overlooked as combined catalytic controls. Three categories of lysosomal machinery drive three distinguishable cycles importing and exporting MR\&P. $\mathrm{Zn}^{2+}$ preemptively inhibits CysHis catalysis under otherwise optimal protonation and reduction. Protein-bound cell $\mathrm{Zn}^{2+}$ concentration is 200-2000 times the non-sequestered inhibitory concentration. Following autophagy, lysosomal proteolysis liberates much inhibitory $\mathrm{Zn}^{2+}$. The vacuolar proton pump is the driving force for $\mathrm{Zn}^{2+}$ export, as well as protonation of the peptidolytic mechanism. Other machinery of lysosomal cycles includes proton-driven $\mathrm{Zn}^{2+}$ exporters (e.g. SLC11A1), $\mathrm{Zn}^{2+}$ channels (e.g. TRPML-1), lysosomal thiol reductase, etc. The CysHis dyad is a sensor of the vacuolar environment of MR\&P, an integrator of these simultaneous variables, and a catalytic responder. Rate-determination can shift between autophagic substrate acquisition (swallowing) and substrate degradation (digesting). $\mathrm{Zn}^{2+}$ recycling from degraded proteins to new proteins is a fourth cycle that might pace lysosomal function under some conditions. Heritable insufficient or excess functions of CysHis cathepsins are associated with dysfunctional inflammation and immunity/auto-immunity, including diabetic pathogenesis.
\end{abstract}

Dept. of Pharmacology, School of Medicine, Wright State University, Dayton, Ohio 45435, USA. E-mail: thomas.lockwood@wright.edu; Tel: +1 9377754402

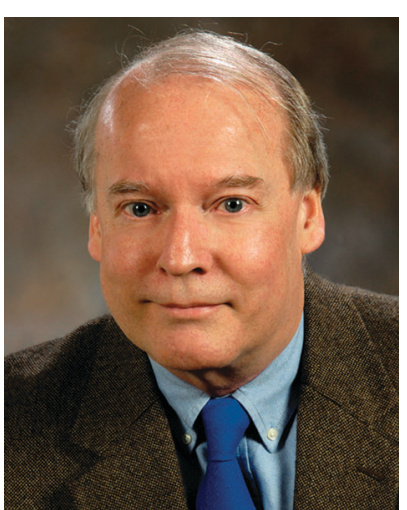

Thomas D. Lockwood
Dr Lockwood received a BA in Biology from Gettysburg College, Gettysburg Pennsylvania, and a PhD from the School of Medicine of the University of Rochester, Rochester, New York. Before joining the Medical School of Wright State University in Dayton, Ohio, he was a research associate at the Salk Institute in La Jolla, California, and assistant professor at the Massachusetts Institute of Technology in Cambridge, Massachusetts. His research interests are the enzymology and physiology of protein degradation, and medical intervention against pathogenic dysfunction.

\section{Introduction}

\subsection{Four lysosomal cycles}

Despite differences in substrate preferences and functions, lysosomal CysHis proteases share much in common. In enzyme assay their maximal catalytic rate requires EDTA and DTT under acid-optimal pH. Recent advances reveal a correspondence between this chemical technology and Nature's engineering. Metals, redox and protons (MR\&P) are regulated by lysosomal machinery as well as enzymologists. These combined variables can grade CysHis catalysis from completely "off" to maximally "on, 1,2 (Fig. 1). Many lysosomal enzymes cooperate in hydrolysis of macromolecular bonds; however, the triple responsiveness of CysHis cathepsins is unique.

Long ago our group wondered whether MR\&P factors might influence CysHis catalysis in lysosomes as well as enzyme assays. We developed a reliable bioassay to measure the release of ${ }^{3} \mathrm{H}$-leucine from degraded proteins of a perfused tissue. Interventions in redox metabolism or metal homeostasis were affirmative $^{3,4}$ (not fully reviewed here). In the following decades, the genome was sequenced; and proteins regulating lysosomal MR\&P have been identified. Dysregulations of lysosomal MR\&P and CysHis cathepsins are now known to be a causative factor in major human diseases. 


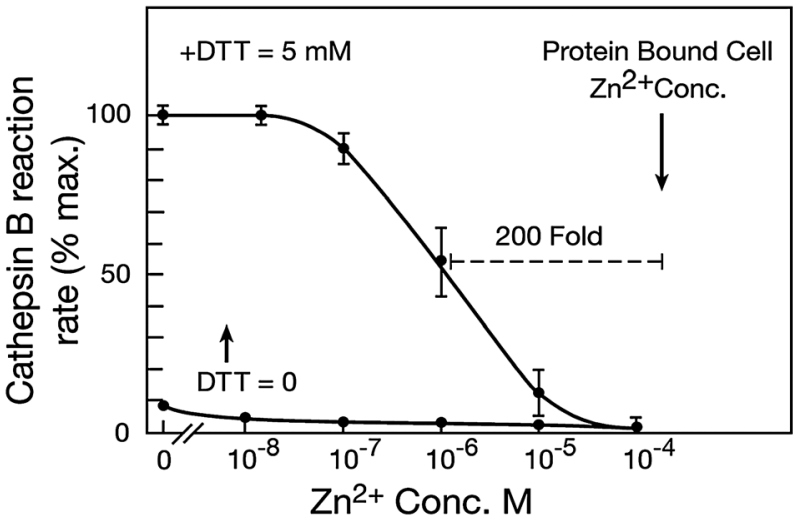

Fig. $1 \mathrm{Zn}^{2+}$ concentration inhibiting cathepsin $\mathrm{B}$ under optimal reduction and protonation. $\mathrm{Zn}^{2+}$ was removed from purified bovine cathepsin B by EDTA followed by exhaustive dialysis. The protease was preliminarily oxidized to the presumptive sulfoxide by incubation in air-equilibrated water. Reaction rate was assayed as previously described by standard methods using fluorimetric detection of the hydrolysis of carbobenzyloxy-ArgArg-AMC (previously reported in Lockwood 2010). The inactive enzyme was placed in reaction buffer (optimal $\mathrm{pH}$ of 5.5) containing the indicated $\mathrm{Zn}^{2+}$ concentrations; and substrate was added. A low activity of the oxidized enzyme was observed (bottom trace). DTT reducing agent $(5 \mathrm{mM})$ was then added to the same reactions; and the reaction rate was again measured. These measurements reveal that a low concentration of $\mathrm{Zn}^{2+}$ preemptively inhibits cathepsin B in the presence of excess DTT activator and optimal $\mathrm{pH}$. Thus, $\mathrm{Zn}^{2+}$ can be an overriding factor limiting the peptidolytic mechanism. Findings were indistinguishable with several $L$ type CysHis cathepsins from various species. $\mathrm{Zn}^{2+}$ concentration bound to cell proteins. Gross, proteinbound $\mathrm{Zn}^{2+}$ concentration per unit of cell volume was measured in perfused myocardial tissue by standard methods using atomic absorption after complete acid hydrolysis of proteins (Lockwood 2010). Extracellular fluid was preliminarily replaced by $\mathrm{Zn}^{2+}$ free perfusion; and results were corrected for extracellular volume. The protein-bound $\mathrm{Zn}^{2+}$ concentration/unit cell volume $(200 \mu \mathrm{M})$ is 200-2000 times the range of $\mathrm{Zn}^{2+}$ concentrations that inhibits CysHis proteases $(0.1-1.0) \mu \mathrm{M}$ or less. However, DTT binds added $\mathrm{Zn}^{2+}$ and decreases its inhibitory potency (see text). Without DTT, $\mathrm{Zn}^{2+}$ partially inhibits at the lowest concentration shown $(0.01 \mu \mathrm{M})$.

This perspective integrates the catalytic properties of CysHis cathepsins with disparate advances in machinery regulating lysosomal MR\&P. Normal functions of CysHis cathepsins are revealed by the consequences of their heritable dysfunction. First, deletion of a single CysHis cathepsin gene can slow lysosomal catalysis. ${ }^{5}$ CysHis cathepsins can serve as lysosomal "pacemakers" under some conditions. Second, single and multiple CysHis cathepsin gene deletions protect against progressive auto-immune tissue damage, ${ }^{6,7}$ and inflammatory damage from pro-catabolic cytokines. ${ }^{8}$ Inflammation and autoimmunity are "double trouble" underlying the pathogenesis of several diseases, including diabetic progression. ${ }^{9}$ Third, heritable dysregulations of lysosomal MR\&P in certain cell types are associated with diseases of insufficient or excessive lysosomal function (see below).

Metallomics and redox proteomics have become routine concepts. ${ }^{10-13}$ However, "multiomics" has not yet entered the lexicon. Thus far, no unifying redox code or metal code has been deciphered in prokaryotes or the compartmentalized cells of eukaryotes. Primordial "omics" has been complicated by the evolution of higher-order protein structure, and separately regulated compartments. There is one type of catalytic mechanism, in one type of compartment, which retains a primitive code of omic control. A proton-responsive enzyme with crossmembership in the redox proteome and metal-interactive proteome is controlled by several simultaneous variables. Semanticists have not yet characterized $\mathrm{pH}$-dependent proteins as the "protonosome". However, the lysosomal compartment regulates these three variables; and these variables regulate CysHis catalysis. Cys confers redox-responsiveness, and His adds metal-responsiveness; together they confer protonresponsiveness. It is proposed here that the CysHis dyad is (a) a sensor of the vacuolar environment of metals, redox and protons, (b) an integrator of these simultaneous variables, and a (c) catalytic responder to cell regulation of the three categories of factors.

Understanding the control of CysHis cathepsins requires decoding the combined effects of metals, redox and protons on the peptidolytic mechanism. In the absence of metals the activity is maximal under optimal $\mathrm{pH}$ near 5.5 , and reductive activation by several mM DTT (Fig. 1). Any of the three members of the governing triumvirate can limit CysHis peptidolysis. However, $\mathrm{Zn}^{2+}(0.1-1.0 \mu \mathrm{M})$ is a preemptive inhibitor despite maximal stimulation by protonation and reduction. The disulfhydryls of DTT bind $\mathrm{Zn}^{2+}$; therefore the actual inhibitory $\mathrm{Zn}^{2+}$ concentration in Fig. 1 is much less than the added concentration. Prior to addition of DTT some amount of inhibition can be observed at the lowest $\mathrm{Zn}^{2+}$ concentration shown $(0.01 \mu \mathrm{M})$ (Fig. 1, bottom trace). The $\mathrm{Zn}^{2+}$ sensitivities of several B- and L-type cathepsins were similar. The triple responsiveness of CysHis cathepsins corresponds to the three categories of lysosomal import-export cycles (Fig. 2). These inputs and outputs displace vacuolar MR\&P from equilibrium conditions. CysHis cathepsins are "wired" to the currents of metals, reducing equivalents and protons created by these cycles. A fourth lysosomal cycle transfers $\mathrm{Zn}^{2+}$ from degraded protein binding sites to new proteins.

\subsection{Scope and limitations of the abstract theory}

Prior to consideration of the present theory, several misperceptions must be dispelled. It is generally presumed that autophagy is the rate-determining step in lysosomal function. However, autophagy and intra-vacuolar degradation can be compared to swallowing and digesting. If intra-vacuolar hydrolysis were always faster than substrate acquisition, then lysosomes would never become loaded with un-degraded macromolecules. In most images of the cell, some lysosomes appear loaded. Microand macro-autophagy have been reviewed many times in recent years, (but not here!). In contrast, intra-vacuolar catalysis has evaded attention thus far. The rate-limitation on lysosomal function can shift between substrate acquisition and substrate degradation under various conditions.

In the absence of inhibitory metal concentration CysHis peptidolysis can function outside the lysosome or cell at a submaximal rate until the enzyme becomes oxidized $^{14}$ (illustrated by the bottom trace in Fig. 1 under low metal concentration). Diverse lysosomal functions have evolved in 


\section{Protein-A.A.-Protein Cycle}

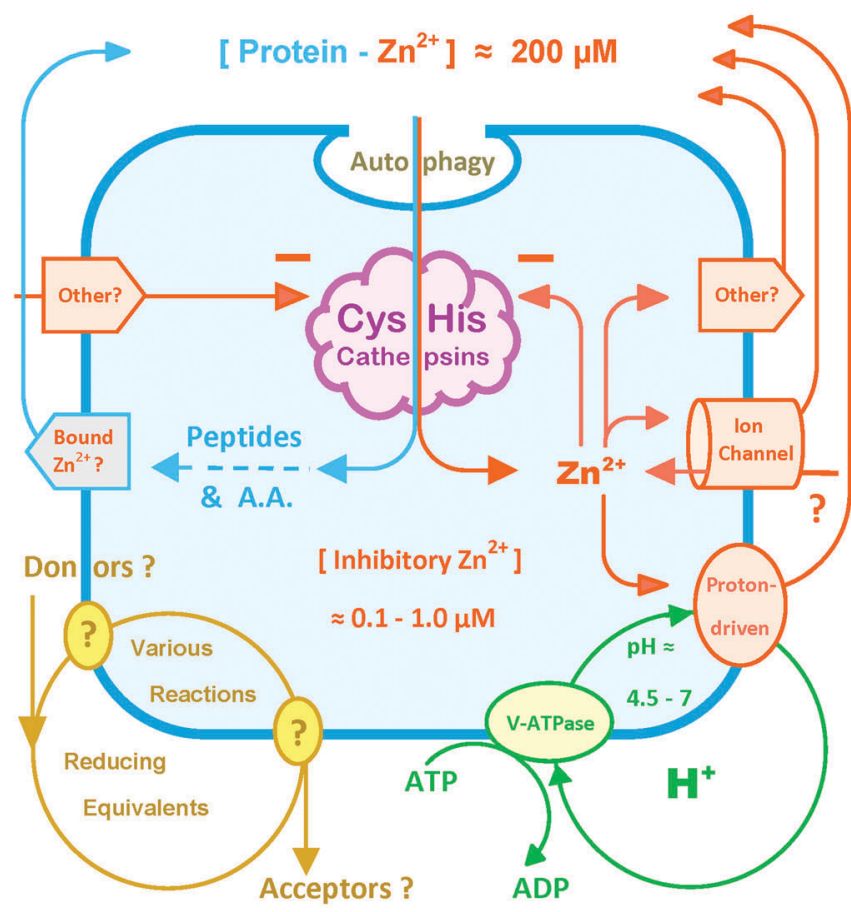

Redox Cycle

Proton Cycle

\section{(Enzymatic \& Non-Enzymatic)}

Fig. 2 Recognition of four lysosomal cycles for future correlation with CysHis cathepsin activity. The peptidolytic chemistry of Fig. 1 challenges molecular biology to account for lysosomal metal, redox and proton (MR\&P) cycles that determine the catalytic environment of CysHis cathepsins. This simplified composite is intended to accommodate future advances in the machinery involved and its integrated control. Following substrate uptake, intra-vacuolar proteolysis liberates a large amount of $\mathrm{Zn}^{2+}$ from macromolecular binding sites; other inhibitory metals might be relevant (see text). Without export, lysosomal $\mathrm{Zn}^{2+}$ would rapidly accumulate to an inhibitory concentration (Fig. 1); and CysHis catalysis would be self-limited. The recycling of released metals from degraded proteins to new proteins might be a rate-determining factor in recycling amino acids into new proteins. The V-ATPase is a major driving force for the export of $\mathrm{Zn}^{2+}$ and other metals via the proton-driven SIC11A1 and other transporters. Conceivable importers and exporters labeled "other" include ATP-binding cassette $(A B C)$ transporters which transport a wide variety of substances that bind $\mathrm{Zn}^{2+}$, e.g. peptides, glutathione, organic cations etc. (and see text). Some TRP channels passively conduct $\mathrm{Zn}^{2+}$ down its electrochemical gradient inward as well as outward. Some TRP channels are phosphorylated or $\mathrm{pH}$ dependent; and some rectify conductance. Multiple, enzymatic and nonenzymatic redox reactions might influence CysHis cathepsins. Pathway(s) transferring reducing equivalents into and out of the lysosome are presently unknown. This abbreviated summary excludes such relevant topics as the cystine exporter, cystinosin, GSH/GSSG transport, lysosomal dipeptidase etc. (see text).

relation to the diversity of specialized cells that employ them. CysHis cathepsins have extra-cellular functions, e.g. degradation of the extra-cellular matrix. This review is generalized to the essential CysHis reaction mechanism within vacuoles. Several topics are postponed until better understanding of their relevance to lysosomal cycles, e.g. the integrity of the lysosomal membrane,${ }^{15}$ activation of the "inflammasome" cascade, ${ }^{16}$ endogenous protease inhibitors, ${ }^{17}$ metabolic and post-receptor signals regulating the lysosomal machinery, etc.

The prokaryotic CysHis catalytic mechanism evolved into cathepsins, caspases and calpains. MR\&P control of intravacuolar catalysis does not conflict with present understanding of extra-lysosomal CysHis proteases (see Section 7).

Lysosomal electrophysiology is presently controversial; ${ }^{18-21}$ and, understanding of integrated $\mathrm{Zn}^{2+}$ transport is presently at the beginning stages. Acceptance of this incomplete theory of catalytic control does not require knowledge of the lysosomal membrane potential or control of all ions. Indeed, this theory provides a guide to unanswered questions.

When disparate advances from many investigators are assembled, Nature's logic becomes self-evident. The present theory is difficult to distinguish from a fact; however, lysosomal MR\&P cycles are initially described here with broad simplicity. Introduction at the preliminary stage is justified by the immediate relevance to pathology and therapeutics. ${ }^{2}$

\section{A lysosomal cycle importing and exporting protons}

Names for different structures of the lysosomal system include: dense granules, pre-lysosomes, endosomes, phagosomes, pinocytic vesicles, macro-autophagic and micro-autophagic vacuoles, endoplasmic reticulum-lysosome fusion bodies, lysosomal-mitochondrial fusion bodies ("lysondrion"), expired lysosomes, residual bodies, exosomes and even "regurgisomes". These various structures have a wide range of $\mathrm{pH}$, redox properties, metal contents and catalytic activities. Here, the criterion of a functional lysosome is a catalytically active vesicle hydrolyzing peptide bonds.

\subsection{Import of lysosomal protons}

Enzymatic and non-enzymatic peptide bond hydrolysis ("splitting by addition of water") is highly dependent upon proton concentration. However, lysosomal proton transport has acquired additional significance in light of other processes that depend on it (Fig. 2). Inactive lysosomes can exist with neutral $\mathrm{pH}$; and active vesicles can decrease $\mathrm{pH}$ below 5 . Progress in regulation of the vacuolar proton pump has been slow due to the complexity of this machine. The structure and function of the V-ATPase in relation to other ions has been reviewed in detail. ${ }^{21}$

If the proton pump is completely inactive, the non-sequestered vacuolar $\mathrm{Zn}^{2+}$ concentration at $\mathrm{pH}$ of 7 might be similar to the cytoplasm. When the proton pump is active, $\mathrm{Zn}^{2+}$ export lowers the inhibitory metal to the permissive concentration for CysHis cathepsin activity (Fig. 1 and 2). The non-sequestered, vacuolar $\mathrm{Zn}^{2+}$ concentration presumably varies inversely with the proton gradient that drives export. However, $\mathrm{Zn}^{2+}$ and proton concentrations might not exist in direct inverse proportionality. Increasing proton concentration drives $\mathrm{Zn}^{2+}$ export while simultaneously protonating the CysHis reaction mechanism, and releasing large amounts of $\mathrm{Zn}^{2+}$ from degraded binding sites. Various TRP 
channels can be influenced or controlled by $\mathrm{Zn}^{2+}, \mathrm{Mg}^{2+}, \mathrm{pH}$, phosphorylation and others. $^{22,23}$

\subsection{Export of lysosomal protons}

A significant route of proton export is direct coupling to metal export (see below). The ability of lysosomes to acidify implies that proton export and leak are small relative to import under maximal function of the V-ATPase.

\section{A lysosomal cycle importing and exporting reducing equivalents, and reducing and oxidizing CysHis cathepsins}

The chemistry of protein thiolation-dethiolation corresponds to the pharmacology of Kosower's sulfhydryl oxidizing agent (diamide) vs. Cleland's sulfhydryl reducing agent (dithiothreitol). Diamide accepts reducing equivalents from two sulfhydryls in a two-step oxidation catalyzing the formation of disulfides. ${ }^{24,25}$ DTT undergoes internal oxidations of its disulfhydryls to disulfides as it transfers to acceptors. Thiolation-dethiolation was demonstrated using one dimensional gel electrophoresis of tissues exposed to diamide. ${ }^{26,27}$ An increase in glutathione disulfide causes corresponding increase in protein-mixed disulfides. An idealized theory suggests that the GSSG/GSH redox ratio controls the functions of some proteins. Redox buffering remains valid in purified reactions; however, application to the compartmentalized cell under non-equilibrium conditions requires modification. ${ }^{25,28}$

Evidence for lysosomal machinery associated with thiolationdethiolation can be summarized with a few findings. In 1993 Stephen et $a .^{29}$ reported that an inactive papain disulfide can be reductively reactivated by $\mathrm{NADPH}$, thioredoxin reductase and thioredoxin in a reconstituted reaction. It was simultaneously reported that pharmacologic thiolation-dethiolation caused by diamide and DTT resulted in large changes in protein degradation in perfused tissue., ${ }^{3,4}$ A lysosomal thioredoxin was then described, ${ }^{30}$ and found to activate lysosomal proteases. ${ }^{31}$ Cathepsin $\mathrm{B}$ is responsive to the redox ratio of GSSG/GSH ${ }^{32}$ as well as a variety of other oxidants. Assembly of these findings suggests transfer of extra-lysosomal reductive energy to oxidized vacuolar CysHis cathepsins. The exact intermediaries and pathways transferring extra-lysosomal reducing energy into the vesicle are unknown. The "redox cycle" shown in Fig. 2 is a generalized composite representing multiple intermediaries and pathways in various cell types and species.

It is now known that thioredoxins and glutaredoxins comprise the major pathways to protein reduction in various compartments. However, thioredoxins and glutaredoxins exhibit cross talk, and some redundant functions. ${ }^{33}$ Indeed, thioredoxins of some compartments are glutathionylated. Glutaredoxins and thioredoxins can both reduce GSSG and PrSSG as well as other oxidation products. Oxidized and reduced glutathione are found in lysosomes as well as the endoplasmic reticulum (ER). Lysosomal transport of some form(s) of glutathione is suspected.
Thus far, functional glutathione reductase and glutaredoxins have not been reported within lysosomes.

\subsection{The oxidation of CysHis cathepsins and export of lysosomal reducing equivalents}

Only the reduced sulfhydryl of CysHis cathepsins is catalytically active. Submaximal activity results from partition of the population of enzyme molecules among the reduced active state and all oxidized inactive states. The partition of catalytic cysteine is the net result of all opposing enzymatic and non-enzymatic redox reactions. Catalytic sulfur can exist in a shifting partition among reversible states until it is irreversibly oxidized. The catalytic partner can oxidize to 2-oxo-histidine. ${ }^{34,35}$ Extensive histidine oxidation seems likely under extreme conditions in some species. However, the significance of histidine redox in mammalian CysHis peptidolysis represents an important gap in present knowledge.

The best single answer to the question of vacuolar CysHis redox is that there is no single answer. CysHis redox within the lysosome can be compared to a busy intersection with crosstraffic from many transferring pathways. The simplified redox cycle of (Fig. 2) represents a multitude of non-enzymatic and enzymatic redox interactions with proteases. This problem is comparable to other cell compartments. ${ }^{36}$ The chemical and biochemical contents of the lysosomal system are undefined to state the least. Lysosomal contents can include any exogenous particle or solute that can be taken up by fluid pinocytosis, phagocytosis or receptor-mediated endocytosis. Moreover, the catabolic vacuole can contain the entire content of the mitochondrion or endoplasmic reticulum. Ongoing processes in mitochondria and ER do not cease instantaneously upon fusion with lysosomes.

Much of what is now known about protein sulfur redox was originally learned using a CysHis protease as experimental tool. Papain permits determination of the redox state of a single protein sulfur site using protease activity as an indicator. This botanical protease has long been available in crystallized form, thereby permitting defined reactions without impurities. ${ }^{37}$ Papain can be "gently" oxidized under conditions that do not cause irreversible inactivation. Far more is known about papain chemistry in purified reactions than papain biology in the cell. Oxidized derivatives of papain sulfur include sulfenic, sulfinic and sulfonic acid (PrSO, $\left.\mathrm{PrSO}_{2}, \mathrm{PrSO}_{3}\right){ }^{38}$ glutathionylations (PrSSG), ${ }^{39,40}$ nitrosylations (PrSNO). ${ }^{41-48}$ Some "deep" oxidation states are not reversible under biological conditions, e.g. $\mathrm{PrSO}_{3}$.

Reactive oxygen species (ROS), reactive nitrogen species (RNS) and the redox ratio of GSSG/GSH are known to be cell signals. Protein sulfoxygenations, nitrosylations and glutathionylations control the functions of some proteins. However, defined redox reactions in purified reconstituted systems can differ greatly from in vivo reactions. An experimental sulfhydryl oxidant can first oxidize and deplete protective GSH, and then oxidize the unprotected protease cysteine directly. In purified enzyme solutions, hydrogen peroxide produces protein sulfenic acids; and nitric oxide donors produce nitrosylations. When competing GSH 
is present, these oxidants first produce GSSG, and then increasingly oxidize proteins as GSH is depleted. ${ }^{47-49}$ Any agent that oxidizes GSH to GSSG can secondarily oxidize Protein-SH to Protein-SSG. Therefore, diverse oxidants act initially to increase the GSSG/GSH ratio and secondarily to oxidize protein sulfhydryls.

Pathways transferring reducing equivalents from lysosomal sulfhydryls to oxygen, or other acceptors, are uncharacterized. Work to be done is illustrated by comparison of known features of redox transfer in the endoplasmic reticulum with corresponding unknowns of the lysosome. The ER has an enzymatic relay system transferring reducing equivalents from internal protein sulfhydryls to oxygen in the process of forming internal disulfide bonds of the folded protein. ${ }^{50-53}$ The ER has multiple pathways of sulfhydryl oxidation in addition to the ER oxidoreductin system (ERO). Dehydroascorbic acid/ascorbic acid redox has been implicated in ER-associated degradation as well as lysosomal degradation. ${ }^{36,53}$ In contrast to cytoplasm, the ER compartment has a high content of glutathionylated proteins and GSSG. Thus far, there has been no suggestion that the ERO relay system is operative in the lysosome after compartmental fusions. Redox implications of lysosomal fusions with other compartments are virtually unstudied.

Speciated metals could participate in the pathways transferring from reduced sulfhydryls of proteins or glutathione to oxygen and other acceptors. (The oxidation state of $\mathrm{Zn}^{2+}$ does not change under biological conditions; although some binding sites are redoxresponsive.) Speciated metals are mutually reactive with protein sulfhydryls and reactive oxygen species or diatomic oxygen. $\mathrm{Fe}^{3+} / \mathrm{Fe}^{2+}$ or $\mathrm{Cu}^{2+} / \mathrm{Cu}^{1+}$ can act as cycling intermediates, and accelerate the transfer of electrons from CysHis cathepsins to oxygen or other acceptors. Speciated metals accelerate the oxidation of CysHis cathepsins in air-equilibrated water. In addition, $\mathrm{Fe}^{3+}$ and $\mathrm{Cu}^{2+}$ (oxidized) directly inhibit CysHis cathepsins. ${ }^{1}$ In contrast, $\mathrm{Fe}^{2+}$ and $\mathrm{Cu}^{1+}$ (reduced) are not potent inhibitors of CysHis cathepsins. Under extreme oxidative conditions (or reductive deficiency) in lower species, ferric and cupric states almost certainly attain sufficient concentrations to directly inhibit CysHis cathepsins.

ROS and RNS are suspected of an influence on CysHis cathepsin function in some specialized cell types. ${ }^{38,41,43-48}$ The superoxide radical is reported to have a role in controlling CysHis cathepsins in macrophages and dendritic cells. ${ }^{54-57}$ Net superoxide levels result from the relative rates of production by NADPH oxidase $v s$. elimination by superoxide dismutase as well as non-enzymatic reactions. The complicated reactions derived from the superoxide radical can produce an oxidative signal in low amounts and pathogenic oxidations in higher amounts. ROS or RNS might also interact with some forms of $\mathrm{Fe}$ or $\mathrm{Cu}$ to oxidize CysHis cathepsins. GSH and the anti-oxidant enzymes, superoxide dismutase, catalase, and peroxidase might all be involved in lysosomal redox of various specialized cell types. ${ }^{58}$ Mitophagy transfers the entire content of the mitochondrion to the catabolic fusion vacuole with unknown consequences.

\subsection{The import of lysosomal reducing equivalents and reduction of CysHis cathepsins}

In the absence of glutaredoxins, GSH activates CysHis cathepsins with less potency than equimolar DTT. ${ }^{32,49}$ Several mM GSH alone can cause an appreciable activation of cathepsins in reaction without metals. Cathepsin B activity is responsive to the ratio of GSSG/GSH as expected of a typical "redox-buffered" protein i.e. increasing GSSG causes increasing inhibition. ${ }^{32}$ Cathepsin L from various species exhibits less sensitivity to the redox ratio of GSSG/GSH (unpublished observation). It should be cautioned that GSSG peptide might compete with peptide substrates without forming a true disulfide bond.

In viable tissue, the responsiveness of proteolysis to diamide vs. DTT is consistent with a contribution of thiolationdethiolation to the control of proteases. ${ }^{3,4}$ In perfused myocardial tissue non-toxic diamide concentrations (100 $\mu \mathrm{M}$ or less), reversibly inhibited all of lysosomal and some of extralysosomal proteolysis $\left({ }^{3} \mathrm{H}\right.$-leucine release from proteins). Following discontinuation of short diamide exposures, cell reductive metabolism could reverse the inhibitory action. After prolonged diamide exposures of 1-2 hours inhibitions were not completely reversible. Following oxidation, GSSG is rapidly exported from this tissue. ${ }^{59}$ Exogenous GSH is not rapidly taken up. Therefore, perfused tissue was exposed to supra-physiologic extracellular GSH concentration in order to replete cell GSH following diamide exposure. Despite toxicity of $1 \mathrm{mM} \mathrm{GSH}$, this high concentration reversed the anti-proteolytic effect of diamide beginning after a lag period.

Consistent with studies on perfused tissue it was reported that reducing equivalents from NADPH can be transferred to the reduction of oxidized papain disulfide via thioredoxin reductase and thioredoxin. ${ }^{29}$ A lysosomal thioredoxin was later identified by its mannose-phosphate destination tag. ${ }^{30}$ The lysosomal reductase co-localizes with vacuolar proteases. ${ }^{31}$ This reductase reduces internal disulfide bonds and unfolds antigens in specialized cells of the immune system..$^{30,31,60}$ However, the lysosomal reductase has been identified in other cell types. Thioredoxins exhibit broad substrate specificity. A reductase that can reduce internal disulfide bonds of proteins can also reduce oxidized sulfur at a protease surface. The lysosomal reductase can activate pro-CysHis cathepsin $B$ and $\mathrm{D}^{31}$ (and see Section 6). Genetic polymorphism in the expression of the lysosomal thiol reductase is associated with diabetic pathogenesis. ${ }^{61}$

The extra-lysosomal origins of vacuolar reducing equivalents, and pathways into the vesicle are unknown (represented as "various reactions" in Fig. 2). The source of reduction of extra-lysosomal thioredoxins is NADPH via thioredoxin reductase. Reduction of the intra-lysosomal thioredoxin-type reductase is puzzling insofar as NADPH dos not cross membranes. Multiple enzymatic and non-enzymatic factors might serve as redox shuttles from extra-lysosomal compartments into the lysosome. ${ }^{32,62}$ Much about redox-dependent proteolysis might be learned from the unusual metabolism of apicomplexan (malarial) parasites $^{63}$ and other parasites.

Many active transporters are capable of moving a wide variety of endogenous and xenobiotic molecules with molecular weights of several hundred e.g. the $\mathrm{ABC}$ transporters (see below). The lysosome is believed to import and export various peptides with broad specificity ${ }^{64,65}$ (Fig. 2). Cystinosis 
is a lysosomal storage disease causing accumulation of vacuolar cystine and lysosomal insufficiency. Cystinosis involves heritable dysfunction of the lysosomal cystine exporter "cystinosin". Cystinosis reveals the normal function of this transporter (not shown in Fig. 2). Lysosomal export of cystine is apparently necessary because the thiol reductase cannot reduce this disulfide bond or cannot reduce it fast enough. Cystine/cysteine is part of redox signaling. ${ }^{66}$ However, the possible roles of cystine/cysteine and GSSG/GSH in lysosomal redox have not been characterized. The lysosome might import and export many redox-active or metal-binding substances that are yet to be discovered.

\section{Lysosomal cycles importing and exporting $\mathrm{Zn}^{2+}$ and other metals}

A slight elevation of extra-cellular $\mathrm{Zn}^{2+}$ can decrease lysosomal proteolysis ${ }^{47}$. Therefore, lysosomal $\mathrm{Zn}^{2+}$ regulation somehow communicates with extra-lysosomal and extra-cellular $\mathrm{Zn}^{2+} \cdot{ }^{67}$ Lysosomal $\mathrm{Zn}^{2+}$ regulation involves trans-membrane $\mathrm{Zn}^{2+}$ gradients; therefore, it is responsive to $\mathrm{Zn}^{2+}$ in other cell compartments. In addition, cytoplasmic $\mathrm{Zn}^{2+}$ might influence signal networks and autophagy.

A vast literature on metal regulation is complicated by several factors. Compartmental $\mathrm{Zn}^{2+}$ regulation results from an interaction among multiple transport mechanisms with opposing vectorial directions. Active lysosomes function under non-equilibrium conditions, with an import/export current of metal ions (Fig. 2). Reported driving forces for lysosomal $\mathrm{Zn}^{2+}$ transport include a proton gradient, a bicarbonate gradient, ${ }^{68}$ the $\mathrm{Zn}^{2+}$ electrochemical gradient, ATP and perhaps others. Different metals share some of the many transport mechanisms summarized below. For example, $\mathrm{Zn}^{2+}$ interacts competitively with the regulation of $\mathrm{Fe}^{2+} \cdot{ }^{6-72}$ Although $\mathrm{Zn}^{2+}$ is emphasized here, $\mathrm{Cu}^{2+}, \mathrm{Fe}^{3+}$ and some other metals can also inhibit CysHis cathepsins.

It is difficult to determine the subcellular location and function of a transporter or channel. The position and transport direction of membrane-associated protein can change under membrane fusions. ${ }^{73}$ The identical metal transporter might be found in the plasma membrane-early endosome of one cell type, and the lysosome of another. Indeed endosomes can recycle to the cell surface or fuse with lysosomes. The locations and functions of various metal transporters, and the primary metal(s) transported might differ in various specialized cells.

The electrophysiology integrating lysosomal $\mathrm{Zn}^{2+}$ translocation with other lysosomal ion regulation is virtually unstudied. This topic involves the lysosomal membrane potential and regulation of all other ions, e.g. bicarbonate, chloride, magnesium, calcium, etc. ${ }^{74}$ The present perspective defers to references ${ }^{18-23,75,76}$ for discussion of lysosomal electrophysiology. If $\mathrm{Zn}^{2+}$ binding to macromolecules or peptides is tight, and dissociation is slow, transport does not conform to principles of ionic electro-physiology. In addition, metallothioneins have a redox-dependent $\mathrm{Zn}^{2+}$ release mechanism. ${ }^{77,78}$
Recent progress in $\mathrm{Zn}^{2+}$ biology has been explosive. Confirmed and likely lysosomal transporters are described by several names due to the history of independent discoveries. The Transporter Classification Database (TCDB) used here is an organization approved by the International Union of Biochemistry and Molecular Biology (IUBMB). ${ }^{79}$ Many metal translocators might be directly or indirectly relevant to the lysosome. Accordingly, Fig. 2 accommodates anticipated progress by representing lysosomal $\mathrm{Zn}^{2+}$ regulation with known and unknown driving mechanisms.

As a beginning, lysosomal $\mathrm{Zn}^{2+}$ homeostasis must be organized as (a) the regulation of the "mobile" or non-bound metal ion, and (b) the regulation of the bound metal that is co-transported with other substances. Cell $\mathrm{Zn}^{2+}$ regulation includes compartmental sequestration, high affinity protein binding, and low affinity buffering involving many substances e.g. citrate, phosphate, amino acids etc. ${ }^{80-83}$ Terms used to describe the biologically effective $\mathrm{Zn}^{2+}$ concentration include "free", "active", "non-bound", "un-buffered", "non-sequestered", "mobile", "chelatable" etc. Perfectly free biological $\mathrm{Zn}^{2+}$ is believed to be in the picoMolar range. For ionic $\mathrm{Zn}^{2+}$ the relevant consideration is the effective electrochemical $\mathrm{Zn}^{2+}$ gradient across the lysosomal membrane, and not the total $\mathrm{Zn}^{2+}$ concentration. The cytoplasmic activity of $\mathrm{Zn}^{2+}$ is

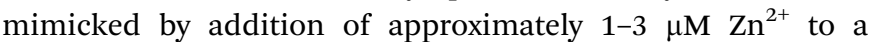
mixture of endogenous $\mathrm{Zn}^{2+}$ buffers at $\mathrm{pH}$ 7. In catalytically active lysosomes the non-bound $\mathrm{Zn}^{2+}$ concentration is presumably maintained near the permissive concentration of $0.1 \mu \mathrm{M}$ (Fig. 1). In inactive vesicles at neutral $\mathrm{pH}$ the $\mathrm{Zn}^{2+}$ concentration might be much higher without the driving force of the proton gradient.

$\mathrm{Zn}^{2+}$ has six coordination sites. Binding can decrease effective collisions and "potency" of $\mathrm{Zn}^{2+}$ without eliminating all reactivity of sites remaining exposed. Therefore, the proper consideration for enzyme inhibition is the effective concentration of interactive $\mathrm{Zn}^{2+}$ sites remaining exposed under all endogenous ligands at some particular $\mathrm{pH}$. Indeed, for some enzymes the effective inhibitory potency of some $\mathrm{Zn}^{2+}$ complexes can be greater than the free ion. ${ }^{84}$ Coordination of $\mathrm{Zn}^{2+}$ with some binding sites need not eliminate fluorophore interactions of ligands remaining exposed. Imaging with cytofluorimetric $\mathrm{Zn}^{2+}$ indicators does not distinguish the sequestered and non-sequestered lysosomal $\mathrm{Zn}^{2+}$ concentration, or electrochemical gradient. ${ }^{85-88}$

Several types of $\mathrm{Zn}^{2+}$ translocators have been identified; however, their driving forces, controls and functions are not well understood. Transporters of non-bound $\mathrm{Zn}^{2+}$ include several families. The mammalian genome codes a family of 14 Zip transporters (TCDB:Slc39a) and 9 ZnT transporters (TCDB:slc30a). ${ }^{82}$ Slc39a14 (or Zip 14) has been reported to be a metal/bicarbonate symporter. ${ }^{89}$ Slc30a (ZnT) transporters function as $\mathrm{Zn}^{2+} / \mathrm{H}^{+}$exchangers. Slc39a transporters are reportedly found in the plasma membrane, whereas Slc30a are have been found in various organelles. The two divalent metal ion transporters (Slc11A1 and Slc11A2) couple the uphill transport of $\mathrm{Zn}^{2+}$ and downhill transport of protons. These proteins also transport $\mathrm{Fe}^{2+}$ in some cell types. ATP binding cassette 
(ABC) transporters couple metal transport to ATP hydrolysis. $\mathrm{ABC}$ transporters are fundamental to metal regulation in bacteria $;{ }^{90,91}$ however, this mechanism is not well characterized in eukaryotes. Humans have more than 50 ABC transporters. Mammalian ABC transporters are known to transport a wide variety of substances that bind $\mathrm{Zn}^{2+}$ (see below). In addition to transporters, mammals have 8 passive Transient Receptor Potential (TRP) channels. These trans-membrane channels conduct non-sequestered metal ions down their electrochemical gradients. Calcium channels have been reported to pass $\mathrm{Zn}^{2+} \cdot{ }^{92,93}$ Omitting the ABC transporters and calcium channels, the combined number of transporters and channels involved in ionic $\mathrm{Zn}^{2+}$ regulation exceeds 30. Many of these might influence lysosomal regulation directly or indirectly. At present, the locations, vectorial orientations, and interactions among these many transporters are not known.

Lysosomal import and export of $\mathrm{Zn}^{2+}$ that is bound to other substances can differ markedly from transport of ionic $\mathrm{Zn}^{2+} \cdot{ }^{94}$ Approximately $10 \%$ of cell proteins and many other substances can bind $\mathrm{Zn}^{2+}$ with a wide range of affinities. ${ }^{95}$ It is suggested that $\mathrm{Zn}^{2+}$ might exchange between high-affinity protein binding sites directly without dissociation into solvent. ${ }^{96}$ The stable $\mathrm{Zn}^{2+}$ interactions with 2Cys2His of many $\mathrm{Zn}^{2+}$ finger proteins are well studied $;{ }^{97}$ however, $\mathrm{Zn}^{2+}$ interactions with $1 \mathrm{Cys} 1 \mathrm{His}$ sites of proteases have received little attention. Regulatory $\mathrm{Zn}^{2+}$ structures with Cys near His include an ion channel; ${ }^{98}$ and metallothionein ${ }^{99}$ as well as the familiar $\mathrm{Zn}^{2+}$ finger motifs.

The ABC transporters include diverse members with a broad range of specificities. Peptides are exported from lysosomes and also imported into lysosomes, probably by $\mathrm{ABC}$ transporters. ${ }^{64,65} \mathrm{GSH}$ and GSSG form protective complexes with metals including $\mathrm{Zn}^{2+}$; and these might share $\mathrm{Zn}^{2+}$ transport via $\mathrm{ABC}$ transporters. ${ }^{100-102} \mathrm{ABC}$ transporters are involved in defenses against metal toxicity in eukaryotic cells. ${ }^{103,104}$ Much about lysosomal metal regulation might be learned from defense against overload of biological and non-biological metals. The broadly specific, ATP-dependent, organic cation transporters might transport $\mathrm{Zn}^{2+}$ that is bound to other substances. Finally, bound $\mathrm{Zn}^{2+}$ might accompany the translocation of peptides via endocytosis, exocytosis and organelle fusions e.g. mitophagy or autophagy. Indeed, a fraction of most proteins can be found in lysosomes, presumably with any $\mathrm{Zn}^{2+}$ that is bound.

\subsection{Selected topics in the lysosomal import of $\mathrm{Zn}^{2+}$ and other metals}

It can be readily estimated that a major route of lysosomal $\mathrm{Zn}^{2+}$ acquisition in active lysosomes is autophagic uptake of proteinbound $\mathrm{Zn}^{2+}$ followed by release upon proteolysis. Approximately $10 \%$ of the proteome has $\mathrm{Zn}^{2+}$ binding sites; and many more proteins bind with lower affinity. Metallothioneins exhibit differential protease susceptibility and intra-lysosomal metal release. ${ }^{105}$ The gross, protein-bound $\mathrm{Zn}^{2+}$ concentration is $200 \mu \mathrm{M}$ (Fig. 2). Basal protein turnover of a typical cell is approximately $2-3 \% \mathrm{~h}^{-1}$. Therefore, each hour $2-3 \%$ of $200 \mu \mathrm{M}$ protein-bound $\mathrm{Zn}^{2+}$ is released from binding sites.
This release rate would increase non-sequestered cell $\mathrm{Zn}^{2+}$ concentration by 4-6 $\mu \mathrm{M}$ per hour if it were uniformly distributed. Approximately half of total protein degradation occurs within lysosomes in most cell types. The active lysosomal volume is only $10-15 \%$ of total cell volume. Therefore, $2-3 \mu \mathrm{M} \mathrm{Zn}{ }^{2+}$ is liberated from degraded proteins into $10-15 \%$ of cell volume each hour. This liberated $\mathrm{Zn}^{2+}$ concentration would be 200-2000 times the concentration that inhibits CysHis cathepsins (0.1-1.0 $\mu \mathrm{M}$, Fig. 1) if released from binding sites without vacuolar export. Without $\mathrm{Zn}^{2+}$ buffering by $5 \mathrm{mM}$ DTT, some inhibition was observed at $0.01 \mu \mathrm{M} \mathrm{Zn}^{2+}$ (Fig. 1, bottom trace). The $0.01 \mu \mathrm{M}$ inhibitory $\mathrm{Zn}^{2+}$ concentration is approximately 10000 fold below the protein-bound cell $\mathrm{Zn}^{2+}$ concentration of $200 \mu \mathrm{M}$. The lifetimes of lysosomes in various cells are not known with precision. However, if vesicles persist for only 0.5-1.0 $\mathrm{h}$, then the $\mathrm{Zn}^{2+}$ liberated from degraded proteins would rapidly accumulate to an inhibitory concentration in the absence of export. Possible inaccuracies of these estimates are quite conservative. Thus, active lysosomes function under a cycle of massive $\mathrm{Zn}^{2+}$ acquisition on substrate proteins, liberation by proteolysis, and export by multiple routes (Fig. 2).

Non-lysosomal compartments might import ionic $\mathrm{Zn}^{2+}$, and then fuse with lysosomes secondarily. Indeed, yeast cells have a $\mathrm{Zn}^{2+}$ storage vacuole for future growth under $\mathrm{Zn}^{2+}$ deficiency. ${ }^{106}$ Some mammalian cells sequester $\mathrm{Zn}^{2+}$ in vacuoles. ${ }^{107}$

\subsection{Selected topics in the lysosomal export of $\mathrm{Zn}^{2+}$ and other metals}

TRPM1-TRPM8 comprise a group of eight ion channels which can pass metals in either direction down the electrochemical gradient. ${ }^{108} \mathrm{Zn}^{2+}$ is reported to regulate its own conductance through a TRP channel with allosteric regulatory kinetics. ${ }^{109-115}$ $\mathrm{Zn}^{2+}$ conductance through some TRP channels is believed to be partially rectified; ${ }^{110,111}$ although the present relevance is unknown. Some TRP channels are responsive to $\mathrm{pH}$ and phosphorylation. ${ }^{22,23,109-114}$ The TRPML-1 channel is of great interest to lysosomal function. ${ }^{114-117}$

The TRPML-1 is found in the lysosomal membranes of diverse cell types. A telling feature is that heritable deficiency of TRPML-1 channel function results in a lysosomal storage disease known as mucolipidosis-IV. ${ }^{117}$ Many variants of lysosomal storage diseases affect all cell types; however, the life-limiting injury is to neural tissue. Mucolipidosis results in accumulation of undegraded macromolecules in large lysosomes of the brain. Eichelsdoerfer et al. ${ }^{118}$ reported: ... "the loss of TRPML1 function results in intracellular chelatable zinc dyshomeostasis. We propose that chelatable zinc accumulation in large lysosomes and membranous vacuoles may contribute to the pathogenesis of the disease and progressive cell degeneration in ML-IV patients"... This disease of denatured protein accumulation implies that a normal function of the TRPML- 1 is net export of lysosomal $\mathrm{Zn}^{2+}$ and perhaps other cell $\mathrm{Zn}^{2+}$ regulation. Mitochondria are also affected. The drosophila ortholog of TRPML-1 is necessary for normal lysosomal function. ${ }^{119}$ The TRPML-1 does not account for all routes of lysosomal $\mathrm{Zn}^{2+}$ export. Complete loss of lysosomal $\mathrm{Zn}^{2+}$ export would presumably be 
embryolethal. Loss of TRPML-1 channel function is also reported to cause disruption of lysosomes and release of cathepsin $\mathrm{B}$ into the cytoplasm. ${ }^{81,120}$ The normal TRPML-1 channel somehow serves in ionic and volume control of the vacuole. ${ }^{121-124}$ The TRPML-1 channel convincingly reveals that $\mathrm{Zn}^{2+}$ export is related to lysosomal function as well as the CysHis cathepsin reaction mechanism (Fig. 1 and 2).

The macrophage protein named "Natural Resistance Associated Membrane Protein 1 (NRAMP1 or SLC11A1) is also fundamentally related to lysosomal function. This protein was originally discovered by the association of microbial infections with loss of its function, hence the name. This gene family has two members: Slc11A1 and Slc11A2; the former is of most interest here. Slc11A1 is expressed in phagocytes, and exports metals from the phagosome. The driving force for uphill lysosomal metal transport is coupling to downhill proton transport. Curiously, insufficient function of Slc11A1 is somehow associated with inability to defend against microbes; and excessive function is associated with a variety of hyper-immune immune syndromes independent of microbes.

Heritable or regulatory alteration of protein function can be caused by structural gene mutations, variations in gene copy number, altered regulation of gene transcription, alternative transcript splicing, RNA interference etc. Beyond the present scope, these combined mechanisms can lead to a wide range of protein content and function among individuals. Regardless of causative mechanism(s), the present theory is the only way to account for all pathogenic results of both insufficient and excess functions of lysosomal metal export.

Slc11A1 can export multiple divalent metal cations from lysosomes, including $\mathrm{Zn}^{2+}$ and $\mathrm{Fe}^{2+}$. The normal function of Slc11A1 was believed to be starvation of phagocytosed microbes for $\mathrm{Fe}^{2+}$ as a growth requirement in specialized phagocytes. This microbicidal mechanism is currently known as "metal withdrawal defense". ${ }^{125}$ The mechanism of immune deficiency that is associated with decreased Slc11A1 function is currently believed to be a failure to starve phagocytosed microbes for $\mathrm{Fe}^{2+}$ and other metals. It has not been appreciated that metal withdrawal defense might interact with an additional microbicidal mechanism of the Slc11A1 exporter. Normal export of inhibitory metals from phagosomes/lysosomes could activate CysHis cathepsins, and increase the degradation of captured microbes while starving them for metal requirements. Conversely, deficiency in the lysosomal export of inhibitory metals would explain protection of endocytosed microbes against destruction by CysHis cathepsins.

Whereas deficient Slc11A1 function is associated with immune deficiency, heritable up-regulation is associated with hyperimmunity. The hyper-immunity that is associated with excessive expression of Slc11A1 is obviously not related to starvation of phagocytosed microbes for Fe. Therefore, the theory of "metal withdrawal defense" cannot account for the pathogenic results of excessive function of the Slc11A1 transporter. It is well known that lysosomal CysHis cathepsins are required for proteolytic antigen processing to immunogenic peptides and presentation to specialized cells of the immune system. ${ }^{126-128}$
Most investigators believe that excessive cell content of the Slc11A1 somehow increases lysosomal proteolytic processing of auto-antigens to immunogenic peptides, thereby increasing auto-immunity. Several CysHis cathepsins are involved in antigen processing. ${ }^{7}$ Autoimmunity can be associated with heritable up-regulation of Slc11A1 expression. Many studies demonstrate a relationship between excessive expression of the Slc11A1 transporter and the auto-immunity of diabetic progression. ${ }^{129-142}$ The result of excessive function of Slc11A1 confirms the relevance of metal export to lysosomal proteolytic function.

Hyper-immunity might be also be associated with excessive lysosomal export of inhibitory $\mathrm{Zn}^{2+}$ and $\mathrm{Fe}^{2+}$ via Slc39A8 (Zip-8). Slc 39A8/ZIP-8 is localized to the lysosomes of at least some cell types. In other cells Slc 39A8 is located on the cell surface and in early endosomes. ${ }^{69-72}$ In a model of T-cell activation and antigen processing, lysosomal slc 39A8 is increased in association with interferon production. ${ }^{143}$ A role of Slc39A8 in lysosomal $\mathrm{Zn}^{2+}$ export upon T-cell activation has been suggested. Such an interpretation would be consistent with an associated role of Slc39A8 in cathepsin activation.

In summary, the normal functions of lysosomal metal regulation in catabolic control are revealed by the results of dysregulations. Defective TRP channel structure, or downregulation of the proton-driven exporter alone can decrease lysosomal $\mathrm{Zn}^{2+}$ export, and cause immune deficiency or a lysosomal storage disease. At the other extreme, excessive function of proton-driven, lysosomal, metal export is associated with excessive lysosomal metal export, and diverse hyperimmune syndromes, e.g. progressive diabetic tissue damage. Optimal lysosomal function exists within some intermediate range between pathogenic excess and insufficiency. All of these observations can be explained by a regulatory contribution of $\mathrm{Zn}^{2+}$, and other metals, to CysHis cathepsin function.

\section{The energy dependence of lysosomal cycles}

The hydrolytic reaction catalyzed by CysHis cathepsins is driven by energy released from the peptide bond. Therefore, the catalyzed reaction is ultimately exergonic. However, maintenance of the maximally active CysHis catalyst has a continual energy requirement. ATP is required for metal export and protonation of the CysHis reaction; and reducing energy is required to oppose protease oxidations. The high-energy phosphate network and redox network are distinguishable systems. After a century of investigation, relationships between the high-energy phosphate network and the redox network involve unanswered questions. ${ }^{144,145}$ Nonetheless, interventions with traditional agents of known actions provide limited information for correlation with future advances.

Experimental demonstration of an ATP requirement for a hypothetical process can lead to the conclusion that fluctuations in cell ATP content control that process. However, a requirement for ATP does not necessarily demonstrate regulation of the process by the permissible range of cell ATP fluctuations. 
Many observed phenomena are co-variables of injury and death under extreme experimental ATP depletion. If the ATP content of a tissue can be decreased to the minimal amount required for sustained viability without changing lysosomal function, then the ATP requirement for proton pumping would not seem to control lysosomal cycles. In perfused myocardium, repeated mitochondrial poisoning and ATP depletion did not decrease lysosomal proteolysis until immediately before functional demise and death. ${ }^{4}$ Thus, the minimal amount of ATP needed to sustain viability of myocardial tissue also suffices to sustain lysosomal cycles. In marked contrast, interventions with non-toxic concentrations of sulfhydryl oxidants and reductants cause large fluctuations in bulk protein degradation with absolutely no change in tissue ATP content or contractile function. Unnecessarily high or prolonged exposures to redox active agents were injurious. Conclusions from mammalian myocardial tissue might not typify the wide range of metabolic conditions observed in all plants, animals and microbes. It is likely that severe, sublethal ATP depletion can limit lysosomal proton pumping and catalysis in some species under some conditions.

\section{Beyond the fact that pro-cathepsin B is a member of the $\mathrm{Zn}^{2+}$ - binding "metallome"}

Most of the cell content of lysosomal hydrolases consists of inactive pro-enzymes. The simultaneous activation of more than 60 acid hydrolases by cleavage of pro-regions remains unexplained. ${ }^{14}$ Active lysosomal proteases can cleave the pro-regions of inactive pro-proteases and other pro-hydrolases. Therefore, all lysosomal proteases can be considered to be convertases activating other lysosomal enzymes. For this reason, it has been presumed that the activation of pro-hydrolases is determined by the ongoing rate of vacuolar proteolysis; and this is not inconsistent with the present theory.

The control of ongoing CysHis peptidolysis by MR\&P cycles could influence normal or abnormal activation of other pro-lysosomal enzymes. Some investigators suspect that lowering $\mathrm{pH}$ alone causes increasing activation of pro-hydrolases. ${ }^{21}$ However, lysosomal $\mathrm{pH}$ is only one component of the MR\&P triumvirate. It has been suggested that the lysosomal reductase system can contribute to activation of pro-cathepsins B and D. ${ }^{31}$ However, it has not been suggested that all three lysosomal cycles conspire to determine the activation of all pro-lysosomal enzymes. The present theory agrees that reducing energy and acidity are positive influences on pro-protease activation; however, it has not been considered that $\mathrm{Zn}^{2+}$ might preemptively oppose these activating influences.

Pro-cathepsin B was discovered objectively in a screen of the $\mathrm{Zn}^{2+}$ - binding proteome. ${ }^{10} \mathrm{~A}$ speculative possibility is that cathepsin B is a primary "trigger protease" for the activation of other lysosomal enzymes, at least in cell types where it is abundant. Cathepsin B can be promptly activated ex vivo either by non-specific inter-molecular proteolytic cleavage of the pro-region or decreasing $\mathrm{pH}$ below 5. Cathepsin $\mathrm{B}$ has a unexplained structure called the occluding loop. The pro-region of Cathepsin B is folded over its catalytic dyad. It has been suggested that cathepsin B auto-activates by self-cleavage of its own pro-region under a $\mathrm{pH}$-dependent conformational change in the occluding loop. ${ }^{146}$ Bound $\mathrm{Zn}^{2+}$ at the catalytic dyad might suppress such self-cleavage of the pro-region by enzymatic activity.

It remains to be determined whether cathepsin $\mathrm{B}$ is the primary convertase activating other proteases in response to lysosomal cycles. Metallomic techniques might not detect metal binding to other pro-proteases that are present in lower amounts. Curiously, gene deletion reveals that cathepsin B is not critical to the life of the mouse due to a degree of functional redundancy. Therefore, cathepsin $\mathrm{B}$ cannot be the only converting mechanism activating lysosomal enzymes. The question of whether pro-hydrolase activation by MR\&P involves cathepsin B or all CysHis cathepsins might depend upon the relative enzyme contents of particular cell types. The liver has a very high content of cathepsin B. Massive hepatic failure causes the lethal, life-limiting tissue damage 12-24 $\mathrm{h}$ following overdose of TNF $\alpha$. As described above, knockout of the cathepsin $\mathrm{B}$ gene alone protects against this lethal receptor-mediated liver damage. $^{8}$

\section{The recycling of amino acids from old proteins to new proteins in association with recycling of metals from degraded binding sites to new binding sites}

Recycling of $\mathrm{Zn}^{2+}$ from degraded proteins to new proteins has all features expected of a crude coordinator of lysosomal and perhaps some extra-lysosomal pathways of proteolysis. Limited studies indicate that extra-lysosomal proteolysis is indeed responsive to redox and $\mathrm{Zn}^{2+}$. This responsiveness includes caspases, ${ }^{147}$ calpains, ${ }^{148}$ and the ubiquitin-proteasome pathway. ${ }^{149-153}$ Cathepsin $\mathrm{B}$ has been found in extra-lysosomal compartments, and is also suspect of extra-lysosomal functions. Oxidative stress is a widely used term that has not been defined. Moderate oxidative stress (or reductive insufficiency) can be a non-injurious part of metabolic control. Moderate oxidative conditions can decrease apoptosis in some cell types. ${ }^{154}$ However, changes induced by $\mathrm{Zn}^{2+}$ and/or redox can involve higher order enzyme structure as well as the catalytic mechanisms discussed here. ${ }^{149,150}$

The reaction mechanism of an active caspase or calpain might serve its specialized function at a small fraction of the maximal catalytic rate. Indeed, non-injurious operation of CysHis cathepsins in vivo might correspond to a small fraction of the optimized rate shown in Fig. 1. Relative sensitivities of lysosomal and extra-lysosomal proteolytic pathways to $\mathrm{Zn}^{2+}$ and redox are uncharacterized. $\mathrm{Zn}^{2+}$ might contribute to coordination of multiple proteolytic pathways. Interestingly, metalloproteases and metallopeptidases require $\mathrm{Zn}^{2+}$ for activity, and do not require a reductive activator. Lysosomal dipeptidase is such a metal-redox independent enzyme. ${ }^{155}$ In summary, diverse extra-lysosomal proteolytic systems are sensitive to $\mathrm{Zn}^{2+}$ 
and redox; however, this responsiveness includes higher-order protein structure.

Pharmacologic interventions against excessive CysHis cathepsin activity can have effective anti-inflammatory actions against diabetic pathogenesis. The most effective drug against progressive diabetic pathogenesis is an anti-lysosomal "zincophore". ${ }^{2}$ However, drug development ${ }^{156,157}$ must be cautious. Normal lysosomal function requires a mid-range between excessive and insufficient function. Many other causes of denatured protein accumulation might interact with excessive anti-lysosomal therapy e.g. Parkinson's disease,${ }^{158}$ Alzheimers disease, ${ }^{159}$ and many lysosomal storage diseases. ${ }^{160}$

\section{References}

1 T. D. Lockwood, Cys-His proteases are among the wired proteins of the cell, Arch. Biochem. Biophys., 2004, 432, 12-24.

2 T. D. Lockwood, The lysosome among targets of metformin: new anti-inflammatory uses for an old drug?, Expert Opin. Ther. Targets, 2010, 14, 467-478.

3 D. P. Thorne and T. D. Lockwood, Four proteolytic processes of myocardium, one insensitive to thiol reactive agents and thiol protease inhibitor, Am. J. Physiol., 1993, 265, E10-E19.

4 T. D. Lockwood, Redox-dependent and redox-independent subcomponents of protein degradation in perfused myocardium, Am. J. Physiol., 1999, 276, E945-E954.

5 J. Dennemärker, T. Lohmüller, S. Müller, S. V. Aguilar, D. J. Tobin, C. Peters and T. Reinheckel, Impaired turnover of autophagolysosomes in cathepsin L deficiency, Biol. Chem., 2010, 391, 913-922.

6 R. Maehr, J. D. Mintern, A. E. Herman, A. M. LennonDumenil, D. Mathis, C. Benoist and H. L. Ploegh, Cathepsin $\mathrm{L}$ is essential for onset of autoimmune diabetes in NOD mice, J. Clin. Invest., 2005, 115, 2934-2943.

7 L. C. Hsing, E. A. Kirk, T. S. McMillen, S. H. Hsiao, M. Caldwell, B. Houston, A. Y. Rudensky and R. C. LeBoeuf, Roles for cathepsins S, L, and B in insulitis and diabetes in the NOD mouse, Autoimmunity, 2010, 34, 96-104.

8 M. E. Guicciardi, H. Miyoshi, S. F. Bronk and G. J. Gores, Cathepsin B knockout mice are resistant to tumor necrosis factor-alpha mediated hepatocyte apoptosis and liver injury: implications for therapeutic applications, Am. J. Pathol., 2001, 159, 2045-2054.

9 J. I. Odegaard and A. Chawla, Connecting Type 1 and Type 2 Diabetes through Innate Immunity, Cold Spring Harbor Perspect. Med., 2012, 2(3), a007724.

10 J. S. Becker, S. Mounicou, M. V. Zoriy, J. S. Becker and R. Lobinski, Analysis of metal-binding proteins separated by non-denaturating gel electrophoresis using matrixassisted laser desorption/ionization mass spectrometry (MALDI-MS) and laser ablation inductively coupled plasma mass spectrometry (LA-ICP-MS), Talanta, 2008, 76, 1183-1188.
11 S. M. Marino, Y. Li, D. E. Fomenko, N. Agisheva, R. L. Cerny and V. N. Gladyshev, Characterization of surfaceexposed reactive cysteine residues in Saccharomyces cerevisiae, Biochemistry, 2010, 49, 7709-7721.

12 M. Thamsen and U. Jakob, The redoxome: Proteomic analysis of cellular redox networks, Curr. Opin. Chem. Biol., 2011, 15, 113-119.

13 D. P. Jones and Y. M. Go, Mapping the cysteine proteome: analysis of redox-sensing thiols, Curr. Opin. Chem. Biol., 2011, 15, 103-112.

14 J. Reiser, B. Adair and T. Reinheckel, Specialized roles for cysteine cathepsins in health and disease, J. Clin. Invest., 2010, 120, 3421-3431.

15 M. J. Sousa, F. Azevedo, A. Pedras, C. Marques, O. P. Coutinho, A. Preto, H. Gerós, S. R. Chaves and M. Côrte-Real, Vacuole-mitochondrial cross-talk during apoptosis in yeast: a model for understanding lysosomemitochondria-mediated apoptosis in mammals, Biochem. Soc. Trans., 2011, 39, 1533-1537.

16 K. Niemi, L. Teirilä, J. Lappalainen, K. Rajamäki, M. H. Baumann, K. Öörni, H. Wolff, P. T. Kovanen, S. Matikainen and K. K. Eklund, Serum amyloid A activates the NLRP3 inflammasome via P2X7 receptor and a cathepsin B-sensitive pathway, J. Immunol., 2011, 186, 6119-6128.

17 M. Volpicella, C. Leoni, A. Costanza, F. De Leo, R. Gallerani and L. R. Ceci, Cystatins, serpins and other families of protease inhibitors in plants, Curr. Protein Pept. Sci., 2011, 12, 386-398.

18 B. E. Steinberg, K. K. Huynh, A. Brodovitch, S. Jabs, T. Stauber, T. J. Jentsch and S. Grinstein, A cation counterflux supports lysosomal acidification, J. Cell Biol., 2010, 189, 1171-1186.

19 L. Wartosch and T. Stauber, A role for chloride transport in lysosomal protein degradation, Autophagy, 2010, 6, 158-159.

20 J. E. DiCiccio and B. E. Steinberg, Lysosomal pH and analysis of the counter ion pathways that support acidification, J. Gen. Physiol., 2011, 137, 385-390.

21 J. A. Mindell, Lysosomal acidification mechanisms, Annu. Rev. Physiol., 2012, 74, 69-86.

22 J. A. Kozak, M. Matsushita, A. C. Nairn and M. D. Cahalan, Charge screening by internal $\mathrm{pH}$ and polyvalent cations as a mechanism for activation, inhibition, and rundown of TRPM7/MIC channels, J. Gen. Physiol., 2005, 126, 499-514.

23 R. H. Chokshi, M. Matsushita and J. A. Kozak, Detailed examination of $\mathrm{Mg}^{2+}$ and $\mathrm{pH}$ sensitivity of human TRPM7 channels, Am. J. Physiol.: Cell Physiol., 2012, 302, C1004-C1011.

24 N. S. Kosower and E. M. Kosower, Diamide: an oxidant probe for thiols, Methods Enzymol., 1995, 251, 123-133.

25 R. E. Hansen, D. Roth and J. R. Winther, Quantifying the global cellular thiol-disulfide status, Proc. Natl. Acad. Sci. U. S. A., 2009, 106, 422-427.

26 L. M. Grimm, M. W. Collison, R. A. Fisher and J. A. Thomas, Protein mixed-disulfides in cardiac cells, 
S-thiolation of soluble proteins in response to diamide, Biochim. Biophys. Acta, 1985, 844, 50-54.

27 M. W. Collison, D. Beidler, L. M. Grimm and J. A. Thomas, A comparison of protein S-thiolation (protein mixeddisulfide formation) in heart cells treated with t-butyl hydroperoxide or diamide, Biochim. Biophys. Acta, 1986, 885, 58-67.

28 A. J. Cooper, J. T. Pinto and P. S. Callery, Reversible and irreversible protein glutathionylation: biological and clinical aspects, Expert Opin. Drug Metab. Toxicol., 2011, 7, 891-910.

29 A. G. Stephen, R. Powls and R. J. Beynon, Activation of oxidized cysteine proteinases by thioredoxin-mediated reduction in vitro, Biochem. J., 1993, 291(Pt 2), 345-347.

30 B. Arunachalam, U. T. Phan, H. J. Geuze and P. Cresswell, Enzymatic reduction of disulfide bonds in lysosomes: characterization of a gamma-interferon-inducible lysosomal thiol reductase (GILT), Proc. Natl. Acad. Sci. U. S. A., 2000, 97, 745-750.

31 O. G. Goldstein, L. M. Hajiaghamohseni, S. Amria, K. Sundaram, S. V. Reddy and A. Haque, Gamma-IFNinducible-lysosomal thiol reductase modulates acidic proteases and HLA class II antigen processing in melanoma, Cancer Immunol. Immunother., 2008, 57, 1461-1470.

32 T. D. Lockwood, Cathepsin B responsiveness to glutathione and lipoic acid redox, Antioxid. Redox Signaling, 2002, 4, 681-691.

33 S. Prast-Nielsen, H. H. Huang and D. L. Williams, Thioredoxin glutathione reductase: its role in redox biology and potential as a target for drugs against neglected diseases, Biochim. Biophys. Acta, 2011, 1810, 1262-1271.

34 C. Schöneich, Mechanisms of metal-catalyzed oxidation of histidine to 2-oxo-histidine in peptides and proteins, J. Pharm. Biomed. Anal., 2000, 21, 1093-1097.

35 D. A. Traoré, A. El Ghazouani, L. Jacquamet, F. Borel, J. L. Ferrer, D. Lascoux, J. L. Ravanat, M. Jaquinod, G. Blondin, C. Caux-Thang, V. Duarte and J. M. Latour, Structural and functional characterization of 2-oxo-histidine in oxidized PerR protein, Nat. Chem. Biol., 2009, 5, 53-59.

36 N. J. Bulleid and L. Ellgaard, Multiple ways to make disulfides, Trends Biochem. Sci., 2011, 36, 485-492.

37 B. Turk, V. Turk and D. Turk, Structural and functional aspects of papain-likecysteine proteinases and their protein inhibitors, Biol. Chem., 1997, 378, 141-150.

38 A. T. Saurin, H. Neubert, J. P. Brennan and P. Eaton, Widespread sulfenic acid formation in tissues in response to hydrogen peroxide, Proc. Natl. Acad. Sci. U. S. A., 2004, 101, 17982-17987.

39 M. Fratelli, E. Gianazza and P. Ghezzi, Redox proteomics: identification and functional role of glutathionylated proteins, Expert Rev. Proteomics, 2004, 1, 365-376, Review.

40 J. M. Hansen, H. Zhang and D. P. Jones, Differential oxidation of thioredoxin-1, thioredoxin-2, and glutathione by metal ions, Free Radicals Biol. Med., 2005, 40, 138-145.

41 G. Venturini, E. Fioravanti, M. Colasanti, T. Persichini and P. Ascenzi, Cys25-nitrosylation inactivates papain, Biochem. Mol. Biol. Int., 1998, 46, 425-428.
42 M. Xian, X. Chen, Z. Liu, K. Wang and P. G. Wang, Inhibition of papain by S-nitrosothiols, Formation of mixed disulfides, J. Biol. Chem., 2000, 275, 20467-20473.

43 R. Sengupta and A. Holmgren, The role of thioredoxin in the regulation of cellular processes by S-nitrosylation, Biochim. Biophys. Acta, 2012, 1820, 689-700.

44 M. W. Foster, M. T. Forrester and J. S. Stamler, A protein microarray-based analysis of S-nitrosylation, Proc. Natl. Acad. Sci. U. S. A., 2009, 106, 18948-18953.

45 G. Venturini, E. Fioravanti, M. Colasanti, T. Persichini and P. Ascenzi, Cys25-nitrosylation inactivates papain, Biochem. Mol. Biol. Int., 1998, 46, 425-428.

46 N. J. Kettenhofen and M. J. Wood, Formation, reactivity, and detection of protein sulfenic acids, Chem. Res. Toxicol., 2010, 23, 1633-1646.

47 M. D. Percival, M. Ouellet, C. Campagnolo, D. Claveau and C. Li, Inhibition of cathepsin $\mathrm{K}$ by nitric oxide donors: evidence for the formation of mixed disulfides and a sulfenic acid, Biochemistry, 1999, 38, 13574-13583.

48 W. S. Lin and D. A. Armstrong, Glutathione mediation of papain inactivation by hydrogen peroxide and hydroxyl radicals, Radiat. Res., 1997, 69, 434-441.

49 G. Lemaire, O. Guittet, M. F. Vesin, M. Lepoivre and M. H. Cottet, Glutathione depletion reveals impairment of antigen processing and inhibition of cathepsin activity by nitric oxide in antigen-presenting cells, Mol. Immunol., 2008, 46, 1100-1108.

50 T. J. Tavender and N. J. Bulleid, Molecular mechanisms regulating oxidative activity of the Ero1 family in the endoplasmic reticulum, Antioxid. Redox Signaling, 2010, 13, 1177-1187.

51 S. Kim, D. P. Sideris, C. S. Sevier and C. A. Kaiser, Balanced Ero1 activation and inactivation establishes ER redox homeostasis, J. Cell Biol., 2012, 196, 713-725.

52 G. Bánhegyi, E. Margittai, A. Szarka, J. Mandl and M. Csala, Crosstalk and barriers between the electron carriers of the endoplasmic reticulum, Antioxid. Redox Signaling, 2012, 16, 772-780.

53 T. D. Lockwood, Inactivation of intracellular proteolysis and cathepsin B enzyme activity by dehydroascorbic acid and reactivation by dithiothreitol in perfused rat heart, Biochem. Pharmacol., 1997, 54, 669-675.

54 E. Godat, V. Hervé-Grvépinet, F. Veillard, F. Lecaille, M. Belghazi, D. Brömme and G. Lalmanach, Regulation of cathepsin K activity by hydrogen peroxide, Biol. Chem., 2008, 389, 1123-1126.

55 F. Meissner, K. Molawi and A. Zychlinsky, Superoxide dismutase 1 regulates caspase-1 and endotoxic shock, Nat. Immunol., 2008, 9, 866-872.

56 J. M. Rybicka, D. R. Balce, M. F. Khan, R. M. Krohn and R. M. Yates, NADPH oxidase activity controls phagosomal proteolysis in macrophages throughmodulation of the lumenal redox environment of phagosomes, Proc. Natl. Acad. Sci. U. S. A., 2011, 107, 10496-10501.

57 J. M. Rybicka, D. R. Balce, S. Chaudhuri, E. R. Allan and R. M. Yates, Phagosomal proteolysis in dendritic cells is 
modulated by NADPH oxidase in a $\mathrm{pH}$-independent manner, EMBO J., 2011, 31, 932-944.

58 M. P. Murphy, A. Holmgren, N. G. Larsson, B. Halliwell, C. J. Chang, B. Kalyanaraman, S. G. Rhee, P. J. Thornalley, L. Partridge, D. Gems, T. Nyström, V. Belousov, P. T. Schumacker and C. C. Winterbourn, Unraveling the biological roles of reactive oxygen species, Cell Metab., 2011, 13, 361-366.

59 T. Ishikawa, H. Esterbauer and H. Sies, Role of cardiac glutathione transferase and of the glutathione S-conjugate export system in biotransformation of 4-hydroxynonenal in the heart, J. Biol. Chem., 1986, 261, 1576-1581.

60 R. Singh and P. Cresswell, Defective cross-presentation of viral antigens in GILT-free mice, Science, 2010, 328, 1394-1398.

61 V. Turcot, L. Bouchard, G. Faucher, A. Tchernof, Y. Deshaies, L. Pérusse, P. Marceau, F. S. Hould, S. Lebel and M. C. Vohl, A polymorphism of the interferon-gammainducible protein 30 gene is associated with hyperglycemia in severely obese individuals, Hum. Genet., 2011, 131, 57-66.

62 M. A. Feeney, K. Veeravalli, D. Boyd, S. Gon, M. J. Faulkner, G. Georgiou and J. Beckwith, Repurposing lipoic acid changes electron flow in two important metabolic pathways of Escherichia coli, Proc. Natl. Acad. Sci. U. S. A., 2011, 108, 7991-7996.

63 S. C. Maughan, M. Pasternak, N. Cairns, G. Kiddle, T. Brach, R. Jarvis, F. Haas, J. Nieuwland, B. Lim, C. Müller, E. Salcedo-Sora, C. Kruse, M. Orsel, R. Hell, A. J. Miller, P. Bray, C. H. Foyer, J. A. Murray, A. J. Meyer and C. S. Cobbett, Plant homologs of the Plasmodium falciparum chloroquine-resistance transporter, PfCRT, are required for glutathione homeostasis and stress responses, Proc. Natl. Acad. Sci. U. S. A., 2010, 107, 2331-2336.

64 M. Thamotharan, Y. B. Lombardo, S. Z. Bawani and S. A. Adibi, An active mechanism for completion of the final stage of protein degradation in the liver, lysosomal transport of dipeptides, J. Biol. Chem., 1997, 272, 11786-11790.

65 I. Bangert, F. Tumulka and R. Abele, The lysosomal polypeptide transporter TAPL: more than a housekeeping factor?, Biol. Chem., 2011, 392, 61-66.

66 Y. M. Go and D. P. Jones, Cysteine/cystine redox signaling in cardiovascular disease, Free Radicals Biol. Med., 2011, 50, 495-509.

67 J. Gibon, P. Tu, S. Bohic, P. Richaud, J. Arnaud, M. Zhu, G. Boulay and A. Bouron, The over-expression of TRPC6 channels in HEK-293 cells favours the intracellular accumulation of zinc, Biochim. Biophys. Acta, 2011, 1808, 2807-2818.

68 D. W. Nebert, M. Gálvez-Peralta, E. B. Hay, H. Li, E. Johansson, C. Yin, B. Wang, L. He and M. Soleimani, ZIP14 and ZIP8 zinc/bicarbonate symporters in Xenopus oocytes: characterization of metal uptake and inhibition, Metallomics, 2012, 4, 1218-1225.
69 J. J. Pinilla-Tenas, B. K. Sparkman, A. Shawki, A. C. Illing, C. J. Mitchell, N. Zhao, J. P. Liuzzi, R. J. Cousins, M. D. Knutson and B. Mackenzie, Zip14 is a complex broad-scope metal-ion transporter whose functional properties support roles in the cellular uptake of zinc and nontransferrin-bound iron, Am. J. Physiol.: Cell Physiol., 2011, 301, C862-C871.

70 A. C. Illing, A. Shawki, C. L. Cunningham and B. Mackenzie, Substrate profile and metal-ion selectivity of human divalent metal-ion transporter-1, J. Biol. Chem., 2012, 287, 30485-30496.

71 S. Jenkitkasemwong, C. Y. Wang, B. Mackenzie and M. D. Knutson, Physiologic implications of metal-ion transport by ZIP14 and ZIP8, Biometals, 2012, 25, 643-655.

72 C. Y. Wang, S. Jenkitkasemwong, S. Duarte, B. K. Sparkman, A. Shawki, B. Mackenzie and M. D. Knutson, ZIP8 Is an Iron and Zinc Transporter Whose Cell-surface Expression Is Up-regulated by Cellular Iron Loading, J. Biol. Chem., 2012, 287, 34032-34043.

73 A. C. Cerny and A. Huber, Regulation of TRP signalling by ion channel translocation between cell compartments, Adv. Exp. Med. Biol., 2011, 704, 545-572.

74 A. Shawki and B. Mackenzie, Interaction of calcium with the human divalent metal-ion transporter-1, Biochem. Biophys. Res. Commun., 2010, 393, 471-475.

75 T. Stauber and T. J. Jentsch, Chloride in Vesicular Trafficking and Function, Annu. Rev. Physiol., 2012, Oct, 17.

76 M. Toei, R. Saum and M. Forgac, Regulation and isoform function of the V-ATPases, Biochemistry, 2010, 49, 4715-4723.

77 W. Maret, Redox biochemistry of mammalian metallothioneins, J. Biol. Inorg. Chem., 2011, 16, 1079-1086.

$78 \mathrm{~W}$. Maret, New perspectives of zinc coordination environments in proteins, J. Inorg. Biochem., 2012, 111, 110-116.

79 M. H. Saier Jr, M. R. Yen, K. Noto, D. G. Tamang and C. Elkan, The Transporter Classification Database: recent advances, Nucleic Acids Res., 2009, 37, D274-D278.

80 K. A. Jackson, R. A. Valentine, L. J. Coneyworth, J. C. Mathers and D. Ford, Mechanisms of mammalian zinc-regulated gene expression, Biochem. Soc. Trans., 2008, 36, 1262-1266.

81 K. Kiselyov, G. A. Colletti, A. Terwilliger, K. Ketchum, C. W. Lyons, J. Quinn and S. Muallem, TRPML: Transporters of metals in lysosomes: essential for cell survival?, Cell Calcium, 2011, 50, 288-294.

82 T. Fukada and T. Kambe, Molecular and genetic features of zinc transporters in physiology and pathogenesis, Metallomics, 2011, 3, 662-674.

83 D. E. Sutherland and M. J. Stillman, The "magic numbers" of metallothionein, Metallomics, 2011, 3, 444-463.

84 D. Sweeney, M. L. Raymer and T. D. Lockwood, Antidiabetic and antimalarial biguanide drugs are metalinteractive antiproteolytic agents, Biochem. Pharmacol, 2003, 66, 663-677.

85 E. M. Nolan and S. J. Lippard, Small-molecule fluorescent sensors for investigating zinc metalloneurochemistry, Acc. Chem. Res., 2009, 42, 193-203. 
86 E. Tomat and S. J. Lippard, Imaging mobile zinc in biology, Curr. Opin. Chem. Biol., 2010, 14, 225-230.

87 M. D. Pluth, E. Tomat and S. J. Lippard, Biochemistry of mobile zinc and nitric oxide revealed by fluorescent sensors, Annu. Rev. Biochem., 2011, 80, 333-355.

88 J. E. Kwon, S. Lee, Y. You, K. H. Baek, K. Ohkubo, J. Cho, S. Fukuzumi, I. Shin, S. Y. Park and W. Nam, Fluorescent Zinc Sensor with Minimized Proton-Induced Interferences: Photophysical Mechanism for Fluorescence Turn-On Response and Detection of Endogenous Free Zinc Ions, Inorg. Chem., 2012, 51, 8760-8774.

89 K. Girijashanker, L. He, M. Soleimani, J. M. Reed, H. Li, Z. Liu, B. Wang, T. P. Dalton and D. W. Nebert, Slc39a14 gene encodes ZIP14, a metal/bicarbonate symporter: similarities to the ZIP8 transporter, Mol. Pharmacol., 2008, 73, 1413-1423.

90 J. S. Klein and O. Lewinson, Bacterial ATP-driven transporters of transition metals: physiological roles, mechanisms of action, and roles in bacterial virulence, Metallomics, 2011, 3, 1098-1108.

91 C. M. Vahling-Armstrong, H. Zhou, L. Benyon, J. K. Morgan and Y. Duan, Two plant bacteria, S. meliloti and Ca. Liberibacter asiaticus, share functional znuABC homologues that encode for a high affinity zinc uptake system, PLoS One, 2012, 7, e37340.

92 S. Hou, L. E. Vigeland, G. Zhang, R. Xu, M. Li, S. H. Heinemann and T. Hoshi, $\mathrm{Zn}^{2+}$ activates large conductance $\mathrm{Ca}^{2+}$-activated $\mathrm{K}^{+}$channel via an intracellular domain, J. Biol. Chem., 2010, 285, 6434-6442.

93 G. Kovacs, T. Danko, M. J. Bergeron, B. Balazs, Y. Suzuki, A. Zsembery and M. A. Hediger, Heavy metal cations permeate the TRPV6 epithelial cation channel, Cell Calcium, 2011, 49, 43-55.

94 S. A. Sinclair and U. Krämer, The zinc homeostasis network of land plants, Biochim. Biophys. Acta, 2012, 1823, 1553-1567.

95 L. Decaria, I. Bertini and R. J. Williams, Zinc proteomes, phylogenetics and evolution, Metallomics, 2010, 2, 706-709.

96 L. C. Costello, C. C. Fenselau and R. B. Franklin, Evidence for operation of the direct zinc ligand exchange mechanism for trafficking, transport, and reactivity of zinc in mammalian cells, J. Inorg. Biochem., 2011, 105, 589-599.

97 T. Simonson and N. Calimet, Cys(x)His(y)- $\mathrm{Zn}^{2+}$ interactions: thiol vs. thiolate coordination, Proteins, 2002, 49, 37-48.

$98 \mathrm{H} . \mathrm{Hu}, \mathrm{M}$. Bandell, M. J. Petrus, M. X. Zhu and A. Patapoutian, Zinc activates damage-sensing TRPA1 ion channels, Nat. Chem. Biol., 2009, 5, 183-190.

99 O. I. Leszczyszyn, C. R. White and C. A. Blindauer, The isolated Cys2His2 site in EC metallothionein mediates metal-specific protein folding, Mol. Biosyst., 2010, 6, 1592-1603.

100 M. W. Carew, H. Naranmandura, C. B. Shukalek, X. C. Le and E. M. Leslie, Monomethylarsenic diglutathione transport by the human multidrug resistance protein 1 (MRP1/ABCC1), Drug Metab. Dispos., 2011, 39, 2298-2304.
101 A. Kreżel, J. Wójcik, M. Maciejczyk and W. Bal, Zn(II) complexes of glutathione disulfide: structural basis of elevated stabilities, Inorg. Chem., 2011, 50, 72-85.

102 E. M. Leslie, Arsenic-glutathione conjugate transport by the human multidrug resistance proteins (MRPs/ABCCs), J. Inorg. Biochem., 2012, 108, 141-149.

103 Y. Long, Q. Li, Y. Wang and Z. Cui, MRP proteins as potential mediators of heavy metal resistance in zebrafish cells, Comp. Biochem. Physiol., Part C: Toxicol. Pharmacol., 2011, 153, 310-317.

104 S. H. Hahn, O. J. Yoo and W. A. Gahl, Effect of metal ions on the stability of metallothionein in the degradation by cellular fractions in vitro, Exp. Mol. Med., 2001, 33, 32-36.

105 J. M. McKim Jr, S. Choudhuri and C. D. Klaassen, In vitro degradation of apo-, zinc-, and cadmium-metallothionein by cathepsins B, C, and D, Toxicol. Appl. Pharmacol., 1992, 116, 117-124.

106 C. Simm, B. Lahner, D. Salt, A. LeFurgey, P. Ingram, B. Yandell and D. J. Eide, Saccharomyces cerevisiae vacuole in zinc storage and intracellular zinc distribution, Eukaryotic Cell, 2007, 6, 1166-1177.

107 H. C. Roh, S. Collier, J. Guthrie, J. D. Robertson and K. Kornfeld, Lysosome-related organelles in intestinal cells are a zinc storage site in C. elegans, Cell Metab., 2012, 15, 88-99.

108 B. Nilius and G. Owsianik, The transient receptor potential family of ion channels, Genome Biol., 2011, 12, 218.

109 S. Lambert, A. Drews, O. Rizun, T. F. Wagner, A. Lis, S. Mannebach, S. Plant, M. Portz, M. Meissner, S. E. Philipp and J. Oberwinkler, Transient receptor potential melastatin 1 (TRPM1) is an ion-conducting plasma membrane channel inhibited by zinc ions, J. Biol. Chem., 2011, 286, 12221-12233.

110 W. Yang, P. T. Manna, J. Zou, J. Luo, D. J. Beech, A. Sivaprasadarao and L. H. Jiang, Zinc inactivates melastatin transient receptor potential 2 channels via the outer pore, J. Biol. Chem., 2011, 286, 23789-23798.

111 W. Yang, J. Zou, R. Xia, M. L. Vaal, V. A. Seymour, J. Luo, D. J. Beech and L. H. Jiang, State-dependent inhibition of TRPM2 channel by acidic pH, J. Biol. Chem., 2010, 285, 30411-30418.

112 X. Cheng, D. Shen, M. Samie and H. Xu, Mucolipins: Intracellular TRPML1-3 channels, FEBS Lett., 2010, 584, 2013-2021.

113 S. Vergarajauregui, R. Oberdick, K. Kiselyov and R. Puertollano, Mucolipin 1 channel activity is regulated by protein kinase A-mediated phosphorylation, Biochem. J., 2008, 410, 417-425.

114 S. Vergarajauregui, J. A. Martina and R. Puertollano, LAPTMs regulate lysosomal function and interact with mucolipin 1: new clues for understanding mucolipidosis type IV, J. Cell Sci., 2011, 124, 459-468.

115 A. A. Soyombo, S. Tjon-Kon-Sang, Y. Rbaibi, E. Bashllari, J. Bisceglia, S. Muallem and K. Kiselyov, TRP-ML1 regulates lysosomal $\mathrm{pH}$ and acidic lysosomal lipid hydrolytic activity, J. Biol. Chem., 2006, 281, 7294-7301. 
116 D. A. Zeevi, S. Lev, A. Frumkin, B. Minke and G. Bach, Heteromultimeric TRPML channel assemblies play a crucial role in the regulation of cell viability models and starvation-induced autophagy, J. Cell Sci., 2010, 123, 3112-3124.

117 C. Curcio-Morelli, F. A. Charles, M. C. Micsenyi, Y. Cao, B. Venugopal, M. F. Browning, K. Dobrenis, S. L. Cotman, S. U. Walkley and S. A. Slaugenhaupt, Macroautophagy is defective in mucolipin-1-deficient mouse neurons, Neurobiol. Dis., 2010, 40, 370-37.

118 J. L. Eichelsdoerfer, J. A. Evans, S. A. Slaugenhaupt and M. P. Cuajungco, Zinc dyshomeostasis is linked with the loss of mucolipidosis IV-associated TRPML1 ion channel, J. Biol. Chem., 2010, 285, 34304-34308.

119 T. Sun, X. Wang, Q. Lu, H. Ren and H. Zhang, CUP-5, the C. elegans ortholog of the mammalian lysosomal channel protein MLN1/TRPML1, is required for proteolytic degradation in autolysosomes, Autophagy, 2011, 7, 1308-1315.

120 G. A. Colletti, M. T. Miedel, J. Quinn, N. Andharia, O. A. Weisz and K. Kiselyov, Loss of lysosomal ion channel transient receptor potential channel mucolipin-1 (TRPML1) leads to cathepsin B-dependent apoptosis, J. Biol. Chem., 2012, 287, 8082-8091.

121 K. Abe and R. Puertollano, Role of TRP channels in the regulation of the endosomal-lysosmal pathway, Physiology, 2006, 26, 14-2.

122 Z. Zhu, Z. Luo, S. Ma and D. Liu, TRP channels and their implications in metabolic diseases, Pfluegers Arch., 2011, 461, 211-223.

123 C. Grimm, S. Hassan, C. Wahl-Schott and M. Biel, Role of TRPML and TPC channels in endolysosomal cation homeostasis, J. Pharmacol. Exp. Ther., 2012, 342, 236-244.

124 B. Lelouvier and R. Puertollano, Mucolipin-3 regulates luminal calcium, acidification, and membrane fusion in the endosomal pathway, J. Biol. Chem., 2011, 286, 9826-9832.

125 M. F. Cellier, P. Courville and C. Campion, Nramp1 phagocyte intracellular metal withdrawal defense, Microbes Infect., 2007, 9, 1662-1670.

126 J. M. Vyas, A. G. Van der Veen and H. L. Ploegh, The known unknowns of antigen processing and presentation, Nat. Rev. Immunol., 2008, 8, 607-618.

127 C. Watts, The endosome-lysosome pathway and information generation in the immune system, Biochim. Biophys. Acta, 2012, 1824, 14-21.

128 C. Stoeckle, P. Quecke, T. Rückrich, T. Burster, M. Reich, E. Weber, H. Kalbacher, C. Driessen, A. Melms and E. Tolosa, Cathepsin S dominates autoantigen processing in human thymic dendritic cells, J. Autoimmun., 2012, 38, 332-343.

129 N. J. Hill, P. A. Lyons, N. Armitage, J. A. Todd, L. S. Wicker and L. B. Peterson, NOD Idd5 locus controls insulitis and diabetes and overlaps the orthologous CTLA4/IDDM12 and NRAMP1 loci in humans, Diabetes, 2000, 49, 1744-1747.

130 L. S. Wicker, G. Chamberlain, K. Hunter, D. Rainbow, S. Howlett, P. Tiffen, J. Clark, A. Gonzalez-Munoz,
A. M. Cumiskey, R. L. Rosa, J. M. Howson, L. J. Smink, A. Kingsnorth, P. A. Lyons, S. Gregory, J. Rogers, J. A. Todd and L. B. Peterson, Fine mapping, gene content, comparative sequencing, and expression analyses support Ctla4 and Nramp1 as candidates for Idd5.1 and Idd5.2 in the nonobese diabetic mouse, J. Immunol., 2004, 173, 164-173.

131 K. Takahashi, J. Satoh, Y. Kojima, K. Negoro, M. Hirai, Y. Hinokio, Y. Kinouchi, S. Suzuki, N. Matsuura, T. Shimosegawa and Y. Oka, Promoter polymorphism of SLC11A1 (formerly NRAMP1) confers susceptibility to autoimmune type 1 diabetes mellitus in Japanese, Tissue Antigens, 2004, 63, 231-236.

132 M. Nishino, H. Ikegami, T. Fujisawa, Y. Kawaguchi, Y. Kawabata, M. Shintani, M. Ono and T. Ogihara, Functional polymorphism in Z-DNA-forming motif of promoter of SLC11A1 gene and type 1 diabetes in Japanese subjects: association study and meta-analysis, Metabolism, 2005, 54, 628-633.

133 P. Courville, R. Chaloupka and M. F. Cellier, Recent progress in structure-function analyses of Nramp protondependent metal-ion transporters, Biochem. Cell Biol., 2006, 84, 960-978.

134 S. Kissler, P. Stern, K. Takahashi, K. Hunter, L. B. Peterson and L. S. Wicker, In vivo RNA interference demonstrates a role for Nramp1 in modifying susceptibility to type 1 diabetes, Nat. Genet., 2006, 38, 479-483.

135 K. Hunter, D. Rainbow, V. Plagnol, J. A. Todd, L. B. Peterson and L. S. Wicker, Interactions between Idd5.1/Ctla4 and other type 1 diabetes genes, J. Immunol., 2007, 179, 8341-8349.

136 B. A. O’Brien, N. S. Archer, A. M. Simpson, F. R. Torpy and N. T. Nassif, Association of SLC11A1 promoter polymorphisms with the incidence of autoimmune and inflammatory diseases: a meta-analysis, J. Autoimmun., 2008, 31, 42-51.

137 O. Ates, L. Dalyan, B. Müsellim, G. Hatemi, H. Türker, G. Ongen, V. Hamuryudan and A. Topal-Sarikaya, NRAMP1 (SLC11A1) gene polymorphisms that correlate with autoimmune versus infectious diseasesusceptibility in tuberculosis and rheumatoid arthritis, Int. J. Immunogenet., 2009, 36, 15-19.

138 Y. D. Dai, I. G. Marrero, P. Gros, H. Zaghouani, L. S. Wicker and E. E. Sercarz, Slc11a1 enhances the autoimmune diabetogenic T-cell response by altering processing and presentation of pancreatic islet antigens, Diabetes, 2009, 58, 156-164.

139 D. Paccagnini, L. Sieswerda, V. Rosu, S. Masala, A. Pacifico, M. Gazouli, J. Ikonomopoulos, N. Ahmed, S. Zanetti and L. A. Sechi, Linking chronic infection and autoimmune diseases: Mycobacterium avium subspecies paratuberculosis, SLC11A1 polymorphisms and type-1 diabetes mellitus, PLoS One, 2009, 4, e7109.

140 S. Sreedharan, O. Stephansson, H. B. Schiöth and R. Fredriksson, Long evolutionary conservation and considerable tissue specificity of several atypical solute carrier transporters, Gene, 2011, 478, 11-18.

141 J. H. Yang, K. Downes, J. M. Howson, S. Nutland, H. E. Stevens, N. M. Walker and J. A. Todd, Evidence of 
association with type 1 diabetes in the SLC11A1 gene region, BMC Med. Genet., 2011, 12, 59.

142 T. Canhamero, B. Reines, L. C. Peters, A. Borrego, P. S. Carneiro, L. L. Albuquerque, W. H. Cabrera, O. G. Ribeiro, J. R. Jensen, N. Starobinas, O. M. Ibañez and M. De Franco, Distinct early inflammatory events during ear tissue regeneration in mice selected for high inflammation bearing Slc11a1 $\mathrm{R}$ and $\mathrm{S}$ alleles, Inflammation, 2011, 34, 303-313.

143 T. B. Aydemir, J. P. Liuzzi, S. McClellan and R. J. Cousins, Zinc transporter ZIP8 (SLC39A8) and zinc influence IFNgamma expression in activated human T cells, J. Leukocyte Biol., 2009, 86, 337-348.

144 F. W. Heineman and R. S. Balaban, Effects of afterload and heart rate on $\mathrm{NAD}(\mathrm{P}) \mathrm{H}$ redox state in the isolated rabbit heart, Am. J. Physiol., 1993, 264, H433-H440.

145 M. R. Laughlin and F. W. Heineman, The relationship between phosphorylation potential and redox state in the isolated working rabbit heart, J. Mol. Cell Cardiol., 1994, 26, 1525-1536.

146 J. R. Pungercar, D. Caglic, M. Sajid, M. Dolinar, O. Vasiljeva, U. Pozgan, D. Turk, M. Bogyo, V. Turk and B. Turk, Autocatalytic processing of procathepsin B is triggered by proenzyme activity, FEBS J., 2009, 276, 660-668.

147 D. K. Perry, M. J. Smyth, H. R. Stennicke, G. S. Salvesen, P. Duriez, G. G. Poirier and Y. A. Hannun, Zinc is a potent inhibitor of the apoptotic protease, caspase-3, A novel target for zinc in the inhibition of apoptosis, J. Biol. Chem., 1997, 272, 18530-18533.

148 R. P. Guttmann and G. Johnson, Oxidative stress inhibits calpain activity in situ, J. Biol. Chem., 1998, 273, 13331-13338.

149 P. Kiss, A. Szabó, E. Hunyadi-Gulyás, K. F. Medzihradszky, Z. Lipinszki, M. Pál and A. Udvardy, $\mathrm{Zn}^{2+}$-induced reversible dissociation of subunit Rpn10/p54 of the Drosophila 26 S proteasome, Biochem. J., 2005, 391, 301-310.

150 A. U. Chouduri, K. Mishina, T. Shimizu, M. Yamazaki, T. Tokumoto and S. Yamada, High affinity $\mathrm{Zn}^{2+}$ inhibitory site(s) for the trypsin-like peptidase of the 20S proteasome, Arch. Biochem. Biophys., 2008, 477, 113-120.
151 M. Chen, Q. Chen, X. W. Cheng, T. J. Lu, H. X. Liu, J. M. Jia, C. Zhang, L. Xu and Z. Q. Xiong, $\mathrm{Zn}^{2+}$ mediates ischemiainduced impairment of the ubiquitin-proteasome system in the rat hippocampus, J. Neurochem., 2009, 111, 1094-1103.

152 G. Arena, R. Fattorusso, G. Grasso, G. I. Grasso, C. Isernia, G. Malgieri, D. Milardi and E. Rizzarelli, Zinc(II) complexes of ubiquitin: speciation, affinity and binding features, Chemistry, 2011, 17, 11596-11603.

153 F. Kriegenburg, E. G. Poulsen, A. Koch, E. Krüger and R. Hartmann-Petersen, Redox control of the ubiquitinproteasome system: from molecular mechanisms to functional significance, Antioxid. Redox Signaling, 2011, 15, 2265-2299.

154 Q. Wei, J. Wang, M. H. Wang, F. Yu and Z. Dong, Inhibition of apoptosis by $\mathrm{Zn}^{2+}$ in renal tubular cells following ATP depletion, Am. J. Physiol. Renal Physiol., 2004, 287, F492-F500.

155 I. Dolenc and M. Mihelic, Purification and primary structure determination of human lysosomal dipeptidase, Biol. Chem., 2003, 384, 317-320.

156 S. P. Fricker, Cysteine proteases as targets for metal-based drugs, Metallomics, 2010, 2, 366-377.

157 M. M. Moran, M. A. McAlexander, T. Bíró and A. Szallasi, Transient receptor potential channels as therapeutic targets, Nat. Rev. Drug Discovery, 2011, 10, 601-620.

158 M. Usenovic, E. Tresse, J. R. Mazzulli, J. P. Taylor and D. Krainc, Deficiency of ATP13A2 leads to lysosomal dysfunction, $\alpha$-synuclein accumulation, and neurotoxicity, J. Neurosci., 2012, 32, 4240-4246.

159 M. Lang, L. Wang, Q. Fan, G. Xiao, X. Wang, Y. Zhong and B. Zhou, Genetic inhibition of solute-linked carrier 39 family transporter 1 ameliorates $a \beta$ pathology in a Drosophila model of Alzheimer's disease, PLoS Genet., 2012, 8, e1002683.

160 A. P. Lieberman, R. Puertollano, N. Raben, S. Slaugenhaupt, S. U. Walkley and A. Ballabio, Autophagy in lysosomal storage disorders, Autophagy, 2012, 8, 719-730. 